\title{
Comparison of right-to-left shunt characteristics in cryptogenic embolic ischemic stroke and non-cardioembolic ischemic stroke
}

\author{
Comparação das características do shunt direita-esquerda em pacientes com AVC \\ isquêmico criptogênio e AVC não cardioembólico \\ Valeria Cristina SCAVASINE', Jamileh Ferreira CHAMMA', Rodrigo BAZAN², Gabriel Pereira BRAGA ${ }^{3}$, \\ Marcos Christiano LANGE1, Viviane de Hiroki Flumignan ZÉTOLA ${ }^{1}$
}

\begin{abstract}
Background: Patent foramen ovale (PFO) has been considered a potential mechanism of embolic stroke of undetermined origin. Objective: The aim of the present study was to identify the features of the right-to-left shunt (RLS) in patients with undetermined embolic ischemic stroke and compare them with those of patients with non-cardioembolic ischemic stroke. Methods: A retrospective study was conducted with 168 patients with stroke and RLS separated into the following two groups: the undetermined embolic stroke group (UES group) and noncardioembolic stroke group (NCES group). All patients were assessed by transcranial Doppler to evaluate the presence and quantification of microembolic signals (MES) at rest and under Valsalva maneuver. Results: Of all patients evaluated in the current study, 96 were included in the UES group and 72 in the NCES group. In the UES group, 65 patients had RLS with $\geq 10$ MES (67.7\%), which was higher than that observed in the NCES group (51.4\%, $p=0.038)$. According to the moment of the cardiac cycle, 75 patients (78.1\%) in the UES group had a positive test at rest compared to $42(58.3 \%)$ in the NCES group ( $p=0.007)$. Conclusions: The current study demonstrated that almost $70 \%$ of patients with undetermined embolic stroke and PFO presented a large RLS and more than 75\% had RLS at rest. These findings suggest that the size of the shunt should be taken into account when evaluating whether PFO could be a possible mechanism underlying cryptogenic stroke.
\end{abstract}

Keywords: Foramen Ovale, Patent; Embolism, Paradoxical; Ultrasonography, Doppler, Transcranial; Stroke; Ischemic Stroke.

\section{RESUMO}

Antecedentes: Uma das potenciais fontes embólicas no acidente vascular cerebral (AVC) de origem indeterminada é o forame oval patente (FOP). Objetivo: O objetivo do presente estudo foi identificar as características do shunt direita-esquerda em paciente com AVC de etiologia indeterminada, presumidamente embólica, e comparar tais características com pacientes apresentando AVC por outras causas não embólicas. Métodos: Trata-se de um estudo retrospectivo com 168 pacientes com AVC e forame oval patente, separados em dois grupos: AVC embólico de etiologia indeterminada e AVC por outras causas não embólicas. Todos os pacientes foram submetidos a Doppler transcraniano, para avaliar a presença de shunt direita-esquerda por meio do teste de embolia paradoxal. Além da quantificação de microbolhas, também foi avaliada a presença de shunt em repouso e sob manobra de Valsalva. Resultado: Do total, 96 pacientes foram incluídos no primeiro grupo (AVC indeterminado) e 72, no segundo grupo (AVC não embólico). No primeiro grupo, 65 pacientes exibiram shunt com passagem de mais de 10 microbolhas (67,5\%), enquanto no segundo grupo isso aconteceu em 51,4\% ( $p=0,038$ ) dos casos. Além disso, 75 pacientes (78,1\%) do primeiro grupo tiveram teste positivo ao repouso, comparados com 42 pacientes (58,3\%) no segundo grupo ( $p=0,007)$. Conclusão: 0 presente estudo demonstrou que até $70 \%$ dos pacientes com AVC de etiologia indeterminada e forame oval apresentaram shunts maiores; em mais de 75\%, houve passagem de microbolhas ao repouso. Esses achados sugerem que as características do shunt, como quantidade de microbolhas e passagem ao repouso, devem ser levadas em consideração na avaliação do FOP como possível mecanismo subjacente ao AVC. Palavras-chave: Forame Oval Patente; Embolia Paradoxal; Ultrassonografia Doppler Transcraniana; Acidente Vascular Cerebral; AVC Isquêmico.

\footnotetext{
¿Universidade Federal do Paraná, Hospital de Clínicas, Departamento de Neurologia, Curitiba PR, Brazil.

¿Universidade Estadual Paulista “Júlio de Mesquita Filho”, Departamento de Neurologia, Botucatu SP, Brazil.

${ }^{3}$ Universidade Federal de Mato Grosso do Sul, Departamento de Neurologia, Campo Grande MS, Brazil.

VCS (iD https://orcid.org/0000-0002-2972-0971; JFC (iD) https://orcid.org/0000-0002-8919-2998; RB (iD) https://orcid.org/0000-0003-3872-308X; GPB (D) https://orcid.org/0000-0001-6798-4591; MCL (ID) https://orcid.org/0000-0002-0405-7157; VHFZ (D) https://orcid.org/0000-0001-8464-9488 Correspondence:Valeria Cristina Scavasine; Email:valeriascavasine@hotmail.com.

Conflict of interest: There is no conflict of interest to declare.

Authors' contributions: VCS: participated in data collection, performed transcranial Doppler ultrasound exams, assisted in the writing of the article and was responsible for the submission; JFC: participated in data collection, performed transcranial Doppler ultrasound exams and assisted in the writing of the article; RB, GPB: performed transcranial Doppler ultrasound exams; MCL: creation of the Stroke Unit database, performed transcranial Doppler exams and revised the article; VHFZ: established the methodological guidelines, participated in creation and organization of Stroke Unit database, performed transcranial Doppler ultrasound exams and revised the article.
}

Received on September 17, 2020; Received in its final form on November 18, 2020; Accepted on December $07,2020$. 


\section{INTRODUCTION}

Up to $30 \%$ of all ischemic stroke events are of undetermined etiology ${ }^{1}$. Paradoxical embolism, related to a right-toleft shunt (RLS) through a patent foramen ovale (PFO), is one of the possible mechanisms ${ }^{2,3,4}$.

$\mathrm{PFO}$, a persistent congenital opening in the interatrial septum, is found in about $25 \%$ of the adult population ${ }^{5}$. In young patients with cryptogenic stroke, this prevalence can be as high as $56 \%{ }^{6,7}$. In 2017, three large randomized controlled trials (RESPECT, CLOSE, and REDUCE) suggested that percutaneous closure of PFO could be more effective than medical therapy in preventing recurrent stroke in patients younger than 60 years, despite increasing the risk of atrial fibrillation/flutter ${ }^{8,9,10}$.

RLS diagnostic screening is performed with contrast transcranial Doppler (c-TCD) or transesophageal echocardiography (TEE), with advantages and disadvantages in each method. c-TCD is a highly sensitive test to assess RLS, but it cannot differentiate between cardiac and pulmonary shunts. On the other hand, c-TCD is not invasive and does not require patient sedation; therefore, the patient is more amenable to undergo an adequate Valsalva maneuver. Many studies have shown high sensitivity and specificity of c-TCD compared to c-TEE ${ }^{11,12,13}$. The aim of the present study was to use c-TCD to identify the features of RLS in patients with embolic cryptogenic ischemic stroke and compare with findings of patients with non-cardioembolic ischemic stroke.

\section{METHODS}

This study was a retrospective analysis of a prospective databank, including patients with ischemic stroke and RLS. These patients were selected from the outpatient clinics of the Hospital de Clínicas of the Universidade Federal do Paraná (UFPR) and of the Universidade Estadual Paulista "Júlio de Mesquita Filho" (UNESP). Patient's selection occurred between March 2014 and October 2016. The study was approved by the local Ethics Committee and the board waived the need for patient consent.

All patients underwent a brain scan (axial computed tomography or magnetic resonance image) to confirm the presence of a lesion consistent with a diagnosis of ischemic stroke. Patients were separated into the following two groups: undetermined embolic stroke group (UES group) and non-cardioembolic stroke group (NCES group).

Inclusion criteria for the UES group were as follows: 1 ) adult patients ( $\geq 18$ years old) with non-lacunar stroke detected by CT or MRI; 2) absence of extracranial or intracranial atherosclerosis causing $\geq 50 \%$ luminal stenosis in arteries supplying the area of ischemia; 3 ) no major-risk cardioembolic source of embolism (confirmed by transthoracic echocardiography and electrocardiogram); 4) no other specific cause of stroke identified (e.g., arteritis, dissection, migraine/vasospasm, drug misuse) ${ }^{14}$.

Inclusion criteria for the NCES group was based on the ASCOD definition: a minimum investigation with echocardiogram (ECG) and transthoracic echocardiogram (TTE) showing absence of cardioembolic mechanism (C1 and $\mathrm{C} 2$ ) plus the presence of one potentially causal mechanism (1) or of uncertain causality (2): atherosclerosis (A), small vessel disease (S), other etiologies (O), or dissection $(D)^{15}$. An exception for this criteria was the combination of PFO and atrial septal aneurysm (ASA), which is classified as $\mathrm{C} 2$ in the ASCOD classification. These patients were included in the statistical analysis if they had normal ECG and TTE, for being considered subject of interest in this study.

The following variables were analyzed: age, sex, and vascular risk factors (hypertension, diabetes mellitus, hyperlipidemia, and smoking habit). The RoPE score was determined and considered in both groups for PFO risk analysis ${ }^{16,17}$. A cutoff of 6 was chosen to identify patients with high risk of mortality and recurrent ischemic events ${ }^{18}$.

The main tool used for diagnosing RLS in all patients was c-TCD (Doppler-Box DWL, Singen, Germany). The studies were performed by trained neurologists with a standard protocol briefly presented as follows. Two 2-MHz pulsed Doppler transducers were fixed with a head frame (DiaMon DWL, Singen, Germany) and both middle cerebral artery (MCA) main stems were concomitantly insonated with the M-mode technique (32 sample gates in each channel) through the temporal window at a depth of 50 to $65 \mathrm{~mm}$ with two spectral gates (bigate technique) $8 \mathrm{~mm}$ apart. For the contrasting solution, we combined $8 \mathrm{~mL}$ of saline solution with $1 \mathrm{~mL}$ of the patient's blood and $1 \mathrm{~mL}$ of air in a 10-mL syringe. The test was repeated three times at rest and three times under provocative maneuvers.

The results from the bigate spectrogram and the M-mode test were combined for each MCA to improve the sensitivity for microembolic sign (MES) identification. All tests were recorded for 60 seconds with an interval of 3 minutes between the tests for posterior analysis.

The MES identification was based on the international criteria $^{19,20}$. RLS shunt was considered present when at least one MES was detected on both spectral gate displays and a bright red color was observed on the m-mode of at least one monitored MCA. The quantification of MES was registered according to the passage during rest and under Valsalva maneuver (VM). The size of the shunt was estimated according to the quantification of microbubbles (MBs). Patients were classified into three levels: no MBs, negative test for RLS; $\leq 10 \mathrm{MBs}$, small or non-significant RLS; >10 MBs or significant RLS. Although there are some cut-off variations, the consensus seems to be that RLS is present if multiple MBs are detected (more than one) and is considered 
significant whenever more than $10 \mathrm{MBs}$ are detected ${ }^{21,22,23,24}$. No complications or adverse events were observed in patients during the tests.

Data were analyzed using STATA/SE 14.1 statistical software (STATA Corp., College Station, TX, USA). Statistical significance was assessed by 2-tailed Fisher's exact test or chi-squared test for categorical variables, Student's $t$-test for continuous variables with normal distribution, and Mann Whitney test for continuous variables without normal distribution. Statistical significance was set at $\mathrm{p}<0.05$.

\section{RESULTS}

Of the 168 patients with ischemic stroke and RLS evaluated in the current study, 96 were included in the UES group and 72 in the NCES group. Demographic variables are presented in Table 1. There were no differences in age and sex between groups. Diabetes was more frequent in the NCES group (9.4 vs. 20.8\%; $\mathrm{p}=0.045$ ), as well as hyperlipidemia ( 29.2 vs. $48.6 \%$; $\mathrm{p}=0.015$ ). A RoPE Score above 6 was found in $33.3 \%$ of the UES patients against $26.4 \%$ in the NCES group, but this difference was not statistically significant $(\mathrm{p}=0.397)$.

In the UES group, 64 patients (66.6\%) were additionally investigated with TEE. Only eight patients (12.5\%) had discordant tests results, with a negative RLS in TEE and positive RLS in c-TCD, which can be explained by increased sensitivity of the c-TCD. In this group, eight patients $(12.5 \%)$ had an associated ASA. In NCES group, 66 patients (92\%) were submitted to TEE and only two (3\%) of them had ASA. In the UES group, prolonged cardiac monitoring for 24 hours was obtained in 27 (28.1\%) patients; none of them presented clinically relevant arrhythmias.

In the UES group, 65 patients (67.7\%) had RLS with $\geq 10$ MES, which was higher than that observed in the NCES group (37 patients [51.4\%], $\mathrm{p}=0.038$ ). Considering the presence of MES at rest or under Valsalva maneuver, 75 patients

Table 1. Comparison of demographic data of both groups of patients based on the stroke mechanism.

\begin{tabular}{|c|c|c|c|c|}
\hline $\begin{array}{l}\text { Stroke } \\
\text { mechanism }\end{array}$ & & UES (96) & NCES (72) & $p$-value \\
\hline Age & mean $\pm S D$ & $53.6 \pm 14.0$ & $52.2 \pm 14.5$ & $0.529 *$ \\
\hline Female sex & n (\%) & $62(64.6)$ & $46(64.8)$ & $1.000 * *$ \\
\hline Hypertension & $\mathrm{n}(\%)$ & $51(53.1)$ & $38(51)$ & $1.000 * *$ \\
\hline $\begin{array}{l}\text { Diabetes } \\
\text { mellitus }\end{array}$ & $\mathrm{n}(\%)$ & $9(9.4)$ & $15(20.8)$ & $0.045 * *$ \\
\hline Hyperlipidemia & n (\%) & $28(29.2)$ & 35 (48.6) & $0.015^{* *}$ \\
\hline $\begin{array}{l}\text { Current } \\
\text { smoker }\end{array}$ & n (\%) & $26(27.1)$ & $27(37.5)$ & $0.180 * *$ \\
\hline RoPE Score $>6$ & n (\%) & 32 (33.3) & 19 (26.4) & $0.397 * *$ \\
\hline
\end{tabular}

UES: undetermined embolic stroke group; NCES: non-cardioembolic stroke group; SD: standard deviation; ${ }^{*}$ Student's $t$-test; ${ }^{*}{ }^{*}$ chi-squared test.
(78.1\%) in the UES group had a positive test at rest compared to $42(58.3 \%)$ in the NCES group $(\mathrm{p}=0.007)$. Table 2 presents RLS characteristics in both groups.

\section{DISCUSSION}

The current study demonstrated that more than two thirds of patients with UES had large shunts. Also, most of them occurred at rest, which was significantly higher compared to patients with NCES mechanism. These findings suggest that, in patients with PFO, there is a link between features of RLS and stroke causality.

Previous studies demonstrated that the RoPE score could stratify the impact of the PFO as the mechanism of ischemic stroke and its recurrence likelihood ${ }^{17}$. This connection was not observed in our study. One possible explanation could be the fact that the RoPE Score is based on the information from the medical history of the patients, neglecting size and moment of the shunt and anatomical issues (association of ASA).

A higher frequency of diabetes mellitus and dyslipidemia was found in patients with NCES compared to patients with UES. This could be explained by the selection criteria for both groups, including patients with small and large vessel disease (A1, A2, S1 and S2) in the NCES group and excluding them from the UES group (no lacunar lesion and the absence of significant extracranial or intracranial atherosclerosis). The relationship between these two risk factors and stroke mechanisms was previously reported in some studies ${ }^{25,26,27}$. On the other hand, a lower prevalence of vascular risk factors in cryptogenic stroke has been very well documented ${ }^{1,28}$.

In the CLOSE trial, a reduction of recurrence was observed in patients with cryptogenic ischemic stroke and PFO treated by percutaneous closure. That trial selected patients with atrial septal aneurysm or large interatrial shunt, a subgroup considered at high risk of recurrence ${ }^{8}$. Meta-analyses including the main PFO studies confirm that patients with large RLS benefit more from PFO closure than those with small $\mathrm{RLS}^{29,30,31}$. In the current study, patients with PFO and undetermined embolic ischemic stroke presented larger RLS than patients with $\mathrm{PFO}$ and atherothrombotic ischemic stroke, suggesting that the quantification of RLS could represent a single marker for embolic stroke related to PFO.

Besides the size of the RLS, another important aspect to be considered is the presence of MES at rest and under

Table 2. Comparison of right-to-left shunt features of both groups based on stroke mechanism.

\begin{tabular}{llccc}
\hline & & UES (96) & NCES (72) & p-value \\
\hline RLS $\geq 10$ & $n(\%)$ & $65(67.7)$ & $37(51.4)$ & $0.038 *$ \\
At rest & $n(\%)$ & $75(78.1)$ & $42(58.3)$ & $0.007 *$ \\
\hline
\end{tabular}

UES: undetermined embolic stroke group; NCES: non-cardioembolic stroke group; RLS: right-to-left shunt; *Fisher's exact test. 
the Valsalva maneuver. In the pathophysiological process, the RLS at rest could represent a "continuous" opened PFO, where the paradoxical embolism could occur at any moment of the cardiac cycle, independent of the venous return increase $\mathrm{e}^{11,18,32}$. This was previously considered in the decision to perform PFO closure ${ }^{19}$.

This study had some important limitations. Patients were selected from an outpatient setting, after the acute phase of stroke. It is possible that we selected patients with a more benign profile by excluding those who died at the hospital or were disabled and could not show up for medical appointments. However, PFO is related to small embolic events more than to malignant infarctions ${ }^{5}$. Besides, for RLS diagnosis, the test sensitivity is the same whether the stroke is acute or chronic.

Patients included in the current study could not be considered as having embolic stroke of undetermined source (ESUS) because not all of them were submitted to at least 24 hours of Holter monitoring, which is an important limitation. Additionally, TEE was not performed in all patients to confirm the diagnosis of associated ASA or the size of the shunt. Meanwhile, c-TCD is a better method than transesophageal echocardiography to quantify the RLS $^{33,34,35}$. Finally, we did not analyze the importance of the current findings in stroke recurrence, as our aim was to study the aspects of the RLS (intensity of the RLS and positivity at rest).

In conclusion, the current study demonstrated that $78 \%$ of patients with undetermined embolic stroke and RLS had positive test results at rest; almost $70 \%$ presented a large RLS. More studies are needed to better elucidate the link between RLS and cryptogenic stroke, but we believe that the features of the shunt should be taken into account for risk stratification and management.

\section{References}

1. Ntaios G, Papavasileiou V, Milionis H, Makaritsis K, Manios E, Spengos K, et al. Embolic strokes of undetermined source in the athens stroke registry: a descriptive analysis. Stroke. 2015 Jan;46(1):176-81. https://doi.org/10.1161/STROKEAHA.114.007240

2. Desai AJ, Fuller CJ, Jesurum JT, Reisman M. Patent foramen ovale and cerebrovascular disease. Nat Clin Pract Cardiovasc Med. 2006 Aug;3(8):446-55. https://doi.org/10.1038/ncpcardio0597

3. Meissner I, Khandheria BK, Heit JA, Petty GW, Sheps SG, Schwartz GL, et al. Patent foramen ovale: innocent or guilty? Evidence from a prospective population-based study. J Am Coll Cardiol. 2006 Jan;47(2):440-5. https://doi.org/10.1016/j.jacc.2005.10.044

4. Di Tullio M, Sacco R, Gopal A, Mohr JP, Homma S. Patent foramen ovale as a risk factor for cryptogenic stroke. Ann Intern Med. 1992 Sep;117(6):461-5. https://doi.org/10.7326/0003-4819-117-6-461

5. Bang OY, Lee MJ, Ryoo S, Kim SJ, Kim JW. Patent foramen ovale and stroke-current status. J Stroke. 2015 Sep;17(3):229-37. https://doi. org/10.5853/jos.2015.17.3.229

6. Webster MWI, Smith HJ, Sharpe DN, Chancellor AM, Swift DL, Bass NM, et al. Patent foramen ovale in young stroke patients. Lancet. 1988 Jul;332(8601):11-2. https://doi.org/10.1016/S0140-6736(88)92944-3

7. Cabanes L, Mas JL, Cohen A, Amarenco P, Cabanes PA, Oubary $P$, et al. Atrial septal aneurysm and patent foramen ovale as risk factors for cryptogenic stroke in patients less than 55 years of age. A study using transesophageal echocardiography. Stroke. 1993 Dec;24(12):1865-73. https://doi.org/10.1161/01.str.24.12.1865

8. Mas J-L, Derumeaux G, Guillon B, Massardier E, Hosseini H, Mechtouff L, et al. Patent foramen ovale closure or anticoagulation vs. antiplatelets after stroke. N Engl J Med. 2017 Sep;377(11):101121. https://doi.org/10.1056/NEJMoa1705915

9. Saver JL, Carroll JD, Thaler DE, Smalling RW, MacDonald LA, Marks DS, et al. Long-term outcomes of patent foramen ovale closure or medical therapy after stroke. N Engl J Med. 2017 Sep; 377:1022-32. https://doi.org/10.1056/NEJMoa1610057

10. Søndergaard L, Kasner SE, Rhodes JF, Andersen G, Iversen HK, Nielsen-Kudsk JE, et al. Patent foramen ovale closure or antiplatelet therapy for cryptogenic stroke. N Engl J Med. 2017 Sep;377:1033-42. https://doi.org/10.1056/NEJMoa1707404

11. Lange MC, Zétola VF, Souza AM, Novak FM, Piovesan EJ, Werneck LC. Intracranial embolism characteristics in PFO patients: A comparison between positive and negative PFO by transesophageal echocardiography: the rule of the nine. J Neurol Sci. 2010 Jun;293(12):106-9. https://doi.org/10.1016/j.jns.2010.02.003

12. González-Alujas T, Evangelista A, Santamarina E, Rubiera M, Gómez-Boscha Z, Rodríguez-Palomares JF, et al. Diagnóstico y cuantificación del foramen oval permeable. ¿Cuál es la técnica de referencia? Estudio simultáneo con Doppler transcraneal, ecocardiografía transtorácica y transesofágica. Rev Esp Cardiol. 2011 Feb;64(2):133-9. https://doi.org/10.1016/j. recesp.2010.10.009

13. Tobe J, Bogiatzi C, Munoz C, Tamayo A, Spence JD. Transcranial Doppler is complementary to echocardiography for detection and risk stratification of patent foramen ovale. Can J Cardiol. 2016 Aug;32(8):986.e9-986.e16. https://doi.org/10.1016/j. cjca.2015.12.009

14. Hart RG, Diener H-C, Coutts SB, Easton JD, Granger CB, O'Donnell MJ, et al. Embolic strokes of undetermined source: the case for a new clinical construct. Lancet Neurol. 2014 Apr;13(4):429-38. https://doi. org/10.1016/S1474-4422(13)70310-7

15. Amarenco P, Bogousslavsky J, Caplan LR, Donnan GA, Wolf ME, Hennerici MG. The ASCOD Phenotyping of Ischemic Stroke (Updated ASCO Phenotyping). Cerebrovasc Dis. 2013;36(1):1-5. https://doi. org/10.1159/000352050

16. Kent DM, Thaler DE; RoPE Study Investigators. The Risk of Paradoxical Embolism (RoPE) Study: Developing risk models for application to ongoing randomized trials of percutaneous patent foramen ovale closure for cryptogenic stroke. Trials. 2011 Jul;12:185. https://doi.org/10.1186/1745-6215-12-185

17. Kent DM, Ruthazer R, Weimar C, Mas JL, Serena J, Homma S, et al. An index to identify stroke-related vs incidental patent foramen ovale in cryptogenic stroke. Neurology. 2013 Aug;81(7):619-25. https://doi. org/10.1212/WNL.0b013e3182a08d59

18. Morais LA, Sousa L de, Fiarresga A, Martins JD, Timóteo AT, Monteiro $\mathrm{AV}$, et al. RoPE score as a predictor of recurrent ischemic events after percutaneous patent foramen ovale closure. Int Heart J. 2018 Nov 28;59(6):1327-32. https://doi.org/10.1536/ihj.17-489

19. Bernd Ringelstein E, Droste DW, Babikian VL, Evans DH, Grosset DG, Kaps M, et al. Consensus on Microembolus Detection by TCD. Stroke. 1998 Mar;29(3):725-9. https://doi.org/10.1161/01.str.29.3.725 
20. Lao AY, Sharma VK, Tsivgoulis G, Frey JL, Malkoff MD, Navarro JC, et al. Detection of right-to-left shunts: comparison between the International Consensus and Spencer Logarithmic Scale criteria.J Neuroimaging. 2008 Oct;18(4):402-6. https://doi.org/10.1111/j.15526569.2007.00218.x

21. Thaler DE, Ruthazer R, Weimar C, Mas JL, Serena J, Di Angelantonio $\mathrm{E}$, et al. Recurrent stroke predictors differ in medically treated patients with pathogenic vs other PFOs. Neurology. 2014 Jul;83(3):221-6. https://doi.org/10.1212/WNL.0000000000000589

22. Wessler BS, Kent DM, Thaler DE, Ruthazer R, Lutz JS, Serena J. The RoPE score and right-to-left shunt severity by transcranial Doppler in the CODICIA Study. Cerebrovasc Dis. 2015;40(1-2):52-8. https://doi. org/10.1159/000430998

23. Fazio G, Ferro G, Carità P, Lunetta M, Gullotti A, Trapani R, et al. The PFO anatomy evaluation as possible tool to stratify the associated risks and the benefits arising from the closure. Eur J Echocardiogr. 2010 Jul;11(6):488-91. https://doi.org/10.1093/ejechocard/jeq003

24. Zetola VF, Lange MC, Scavasine VC, Bazan R, Braga GP, Leite ACCB, et al. Latin American consensus statement for the use of contrastenhanced transcranial ultrasound as a diagnostic test for detection of right-to-left shunt. Cerebrovasc Dis. 2019;48(3-6):99-108. https:// doi.org/10.1159/000503851

25. Tuttolomondo A, Pinto A, Salemi G, Di Raimondo D, Di Sciacca R, Fernandez P, et al. Diabetic and non-diabetic subjects with ischemic stroke: differences, subtype distribution and outcome. Nutr Metab Cardiovasc Dis. 2008 Feb;18(2):152-7. https://doi.org/10.1016/j. numecd.2007.02.003

26. Tirschwell DL, Smith NL, Heckbert SR, Lemaitre RN, Longstreth WT Jr, Psaty BM. Association of cholesterol with stroke risk varies in stroke subtypes and patient subgroups. Neurology. 2004 Nov;63(10):186875. https://doi.org/10.1212/01.wnl.0000144282.42222.da

27. Herrington W, Lacey B, Sherlike P, Armitage J, Lewington S. Epidemiology of atherosclerosis and the potential to reduce the global burden of atherothrombotic disease. Circ Res. 2016 Feb;118(4):535-46. https://doi.org/10.1161/CIRCRESAHA.115.307611

28. Hart RG, Catanese L, Perera KS, Ntaios G, Connolly SJ. Embolic stroke of undetermined source: a systematic review and clinical update. Stroke. 2017 Apr;48(4):867-72. https://doi.org/10.1161/ STROKEAHA.116.016414

29. Ahmad Y, Howard JP, Arnold A, Shin MS, Cook C, Petraco R, et al. Patent foramen ovale closure vs. medical therapy for cryptogenic stroke: a meta-analysis of randomized controlled trials. Eur Heart J. 2018 May;39(18):1638-49. https://doi.org/10.1093/eurheartj/ ehy 121

30. Akobeng AK, Abdelgadir I, Boudjemline Y, Hijazi ZM. Patent foramen ovale (PFO) closure versus medical therapy for prevention of recurrent stroke in patients with prior cryptogenic stroke: A systematic review and meta-analysis of randomized controlled trials. Catheter Cardiovasc Interv. 2018 Jul;92(1):165-73. https://doi. org/10.1002/ccd.27615

31. Ntaios G, Papavasileiou V, Sagris D, Makaritsis K, Vemmos K, Steiner T, et al. Closure of patent foramen ovale versus medical therapy in patients with cryptogenic stroke or transient ischemic attack. Stroke. 2018 Feb;49(2):412-8. https://doi.org/10.1161/ STROKEAHA.117.020030

32. Saqqur M, Dean N, Schebel M, Hill MD, Salam A, Shuaib A, et al. Improved detection of microbubble signals using power m-mode Doppler. Stroke. 2004 Jan;35(1):e14-7. https://doi.org/10.1161/01. STR.0000106771.62928.66

33. Lange MC, Zétola VF, Souza AM, Piovesan EJ, Muzzio JA, Germiniani JMB, et al. Transcranial Doppler for patent foramen ovale screening. Arq Neuropsiquiatr. 2008 Dec;66(4):785-9. https://doi.org/10.1590/ s0004-282x2008000600001

34. Katsanos AH, Psaltopoulou T, Sergentanis TN, Frogoudaki A, Vrettou AR, Ikonomidis I, et al. Transcranial Doppler versus transthoracic echocardiography for the detection of patent foramen ovale in patients with cryptogenic cerebral ischemia: A systematic review and diagnostic test accuracy meta-analysis. Ann Neurol. 2016 Apr;79(4):625-35. https://doi.org/10.1002/ana.24609

35. Mahmoud NA, Elgendy IY, Agarwal N, Tobis JM, Mojadidi MK. Identification and Quantification of Patent Foramen OvaleMediated Shunts: Echocardiography and Transcranial Doppler. Interv Cardiol Clin. 2017 Oct;6(4):495-504. https://doi.org/10.1016/j. iccl.2017.05.002 